\title{
Association of Cord Blood Resistin with Neonatal Birth Weight and Gestational Age
}

\author{
Shahnaz Pourarian ${ }^{1}$, Saeed Fotouhikia ${ }^{1}$ and Forough Saki ${ }^{2, *}$ \\ ${ }^{1}$ Neonatal Research Center, School of Medicine, Shiraz University of Medical Sciences, Shiraz, Iran \\ ${ }^{2}$ Shiraz Endocrinology and Metabolism Research Center, Shiraz University of Medical Sciences, Shiraz, Iran \\ "Corresponding author: Shiraz Endocrinology and Metabolism Research Center, Shiraz University of Medical Sciences, Shiraz, Iran. Tel: +98-9177127122, Fax: +98-7136473096, \\ Email: forughs@yahoo.com
}

Received 2018 February 04; Revised 2018 July 07; Accepted 2018 October 01.

\begin{abstract}
Background: Resistin is an adipocyte-secreted hormone with critical roles in energy, lipids, and glucose homeostasis. However, its specific role during fetal and neonatal period remains poorly understood.

Methods: This cross sectional study included 160 neonates in four groups of term-AGA, term-SGA, preterm-AGA, and preterm-SGA. Body measurements, blood sugar, and cord blood resistin were evaluated.

Results: In SGA-preterm neonates: Resistin had reverse correlation with birth weight $(\mathrm{P}=0.006)$ and positive correlation with gestational age $(\mathrm{P}=0.002)$. In $\mathrm{SGA}$-term ones resistin had positive correlation with gestational age $(\mathrm{P}=0.041)$.

Conclusions: Cord blood resistin has a positive correlation with gestational age and a reverse association with neonatal birth weight. We suggest that these two different associations might be the cause of conflicting results in previous reports.
\end{abstract}

Keywords: Cord Blood, Resistin, Birth Weight, Gestational Age

\section{Background}

Resistin is a cysteine-rich peptide hormone that is secreted by adipocytes. The discovery of resistin goes back to 2001 and to the group of Lazar from the University of Pennsylvania. It was called "resistin" due to its observed insulin resistance in injected mice (1). It is evident that resistin is an adipocyte-secreted hormone with critical roles in energy, lipids, and glucose homeostasis. However, its specific roles during fetal and neonatal periods remain poorly understood (1-4). Several studies have provided support for the concept where insulin resistance and obesity are associated with a decreased resistin expression, which is regulated by many factors such as thiazolidinediones, tumor necrosis factor alpha, insulin, and growth hormone $(5,6)$. Some studies showed that umbilical cord resistin level had a positive association with maternal resistin level and it was associated with the gestational age and birth weight (7, 8). Another study showed that adiponectins are involved in insulin resistance during gestation, however, Resistin seems to have a minor role (9). Thus, some studies showed that the umbilical cord blood resistin was not correlated with the type of delivery, neonate's gender, maternal age or body mass index (BMI), and neonatal birth weight $(8,10)$. Yeung et al. revealed that newborn blood adipokines are associated with birth outcomes, especially preterm birth and small for gestational age neonate (SGA) (11).

Due to conflicting data regarding the relationship between serum resistin and neonatal growth, the controversies between this association in term, and preterm neonates or appropriate for gestational age (AGA) and SGA ones, the present study focuses on the relevance between the resistin level in the umbilical cord serum and fetal birth weight in AGA and SGA versus term and preterm newborns.

\section{Methods}

\subsection{Study Participants}

This cross sectional study included 160 neonates in four groups of term-AGA, term-SGA, preterm-AGA, and preterm-SGA that were randomly selected from all the liveborn deliveries in the tertiary academic obstetric hospitals of Shiraz University of Medical Sciences, during April 2015 to September 2016.

Infant's growth was monitored by assigning the size and weight throughout the intrauterine life as well as the time of birth. According to the previous definition, AGA describes infants weighted between 90 th and 10th percentile 
with the normal size for his or her gestational age (12). Infants weighing below the 10th percentile who developed less than normal are considered SGA (small for gestational age) (12).

Newborns with congenital anomalies, asphyxia chromosome, abnormalities, and symptoms of TORCH infections including hepatosplenomegaly, microphthalmia, cataract, and microcephaly were excluded. Newborns of women with diabetes, women with medication usage (e.g. antihypertensive, insulin and thyroid hormones) in the recent pregnancy, women with history of Chorioamnionitis, TORCH infections, and women who had PROM $>18$ hours were not included in this study.

\subsection{Ethical Considerations}

Our study was approved by the Ethics Committee of Shiraz University of Medical Sciences. Informed consent was provided and signed by all parents of the newborns after they had been informed about the study. Mothers were advised that they could continue or leave the study at any time. Maternal and neonatal data as well as the result were archived confidentially.

\subsection{Body Measurements and Biochemical Studies}

Gestational age was determined based on the ultrasonic measurements during the first trimester of pregnancy, physical examination, and the New Ballard Score (NBS) (13). We have also registered the age, weight, and length of mothers (after pregnancy), infant sex, length, and head circumference of infants with the standard methods in this study (8).

Measuring of the maternal weight was done by one physician with a standard scale (Seca, Germany), while the mothers wore a light dress and no shoes. Weight was rounded to the nearest $0.1 \mathrm{~kg}$. Mothers' heights were measured using a wall-mounted stadiometer (Seca, model 220, Hamburg, Germany) and rounded to the nearest $0.5 \mathrm{~cm}$. Standard method (weight/height ${ }^{2}, \mathrm{Kg} / \mathrm{m}^{2}$ ) was used to calculate the maternal body mass index (BMI). The height and weight characteristics of newborns were obtained by the same physician at the time of the blood specimen collection and recorded in the clinical encounter form. Newborns were weighted on a portable electronic Seca scale (Seca, Germany) and their length measured by a modified infant calibrated length board (Algen, USA).

According to the standard methods, cord blood sampling was done at the time of birth $(8,14)$. Simultaneously, newborn blood glucose was measured with the ACCUCHEK Glucometer device (made in Germany) in the delivery room. Resistin concentration in sera was measured by using ELISA kits from BOSTER Immuno-Leader Company (USA), according to manufacturer's instructions.

\subsection{Statistical Analysis}

Mean and standard deviation of parameters were computed for the outcomes. Normality of data distribution was verified using The Kolmogorov-Smirnov test. MannWhitney test was used for assessing the comparisons of non-normally distributed data and Student's $t$-test for normally distributed variables. Pearson's test was used for finding the correlations between normally distributed data and Spearman's Ranking test for non-normally distributed ones. Chi-square test was used for comparison of qualitative data. The obtained data were analyzed using the SPSS V. 18 software.

\section{Results}

A total of 160 neonates, including 40 term-AGA (24 male, 16 female), 40 preterm-AGA (26 male, 14 female), 40 term-SGA (17 male, 23 female), and 40 preterm-SGA (19 male, 21 female) were enrolled in this study. $25 \%$ of term and $47 \%$ of preterm deliveries were cesarean section. Table 1 summarized the characteristics of 80 AGA and 80 SGA neonates and their related comparisons. It is evident that body measurements of SGA and their serum blood sugar were significantly lower than AGA neonates $(\mathrm{P}<0.001$ and 0.047 , respectively), however, cord blood resistin did not have any difference $(\mathrm{P}=0.359)$. Cord blood resistin did not have any association with blood glucose level in AGA or SGA neonates $(\mathrm{P}=0.974$, and $\mathrm{P}=0.362$, respectively). Table 2 showed the general characteristics of 80 term and 80 preterm neonates and their difference. It revealed that gestational age and body measurements of term neonates were more than the preterm ones $(\mathrm{P}<0.001)$, however, cord blood resistin and blood sugar of term neonates did not have any significant difference with preterm ones $(\mathrm{P}=$ 0.175 , and $\mathrm{P}=0.672$, respectively). In addition, there is no association between blood sugar and cord blood resistin in either term or preterm neonates $(\mathrm{P}=0.158$, and $\mathrm{P}=0.919$, respectively).

In all neonates, there is no significant association between umbilical cord blood resistin level and the following factors: Birth weight $(P=0.312)$, gestational age $(P=0.216)$, maternal age $(\mathrm{P}=0.973)$, BMI $(\mathrm{P}=0.184)$, neonate's length (0.176) and head circumference $(P=0.327)$, type of delivery $(\mathrm{P}=0.567)$, and neonate's gender $(\mathrm{P}=0.98)$. However, after repeating this analysis in the separated groups of termAGA, preterm-AGA, term-SGA, and preterm-SGA, interesting results were found.

In SGA-preterm group:

1. Resistin level had reverse correlation with birth weight $(\mathrm{P}=0.006)$.

2. For every one unit $(1 \mathrm{~g})$ increase in birth weight, $0.045 \mathrm{ng} / \mathrm{dL}$ decrease in resistin level was observed. 


\begin{tabular}{|c|c|c|c|c|c|}
\hline \multirow{2}{*}{ Factors Studied } & \multicolumn{2}{|c|}{ AGA } & \multicolumn{2}{|c|}{ SGA } & \multirow{2}{*}{ P Value } \\
\hline & Mean \pm SD & Range & Mean \pm SD & Range & \\
\hline Gestational age (wk) & $34.6 \pm 3.9$ & $27-41$ & $35.4 \pm 3.5$ & $26-41$ & 0.179 \\
\hline Maternal age $(y)$ & $28.9 \pm 5.7$ & $18-42$ & $28.4 \pm 4.8$ & $17-38$ & 0.510 \\
\hline Maternal BMI $\left(\mathrm{kg} / \mathrm{m}^{2}\right)$ & $29.5 \pm 5.0$ & $20.31-46.06$ & $29.5 \pm 4.4$ & $18.82-41.11$ & 0.992 \\
\hline Umbilical cord blood sugar $(\mathrm{mg} / \mathrm{dL})$ & $82.3 \pm 20.7$ & $37-156$ & $75.4 \pm 22.3$ & $31-151$ & 0.047 \\
\hline Birth weight (g) & $2378.5 \pm 869.1$ & $850-4200$ & $1806.1 \pm 596.2$ & $500-3000$ & $<0.001$ \\
\hline Neonate's length (cm) & $45.9 \pm 6.0$ & $30-56$ & $42.6 \pm 5.8$ & $21-51$ & 0.001 \\
\hline Neonate's head circumference $(\mathrm{cm})$ & $32.0 \pm 3.4$ & $24-38.5$ & $30.2 \pm 3.7$ & $15-37$ & 0.002 \\
\hline Cord blood resistin (ng/mL) & $26.3 \pm 31.5$ & $4.71-189$ & $22.8 \pm 12.3$ & $2.89-57.79$ & 0.359 \\
\hline \multirow{2}{*}{ Factors Studied } & \multicolumn{2}{|c|}{ Term } & \multicolumn{2}{|c|}{ Preterm } & \multirow{2}{*}{ P Value } \\
\hline & Mean \pm SD & Range & Mean \pm SD & Range & \\
\hline Gestational age (wk) & $38.0 \pm 1.1$ & $37-41$ & $32.0 \pm 3.0$ & $26-36$ & $<0.001$ \\
\hline Maternal age $(y)$ & $28.0 \pm 5.1$ & $18-42$ & $29.3 \pm 5.4$ & $17-40$ & 0.111 \\
\hline Maternal BMI $\left(\mathrm{kg} / \mathrm{m}^{2}\right)$ & $29.0 \pm 4.2$ & $19.11-38.98$ & $30.1 \pm 5.1$ & $18.82-46.06$ & 0.143 \\
\hline Umbilical-cord blood glucose (mg/dL) & $79.5 \pm 19.8$ & $31-146$ & $78.1 \pm 23.6$ & $37-156$ & 0.672 \\
\hline Birth weight (g) & $2663.6 \pm 566.5$ & $1582-4200$ & $1513.9 \pm 530.5$ & $500-2970$ & $<0.001$ \\
\hline Neonate's length $(\mathrm{cm})$ & $47.9 \pm 3.4$ & $40-56$ & $40.5 \pm 6.1$ & $21-51$ & $<0.001$ \\
\hline Neonate's head circumference $(\mathrm{cm})$ & $33.3 \pm 1.8$ & $28-37$ & $28.9 \pm 3.7$ & $15-38.5$ & $<0.001$ \\
\hline Cord blood resistin (ng/mL) & $21.9 \pm 9.8$ & $4.71-45.9$ & $27.1 \pm 32.2$ & $2.89-189$ & 0.175 \\
\hline
\end{tabular}

3. Resistin level had a positive correlation with gestational age $(\mathrm{P}=0.002)$.

4. For every one unit (one week) increase in gestational age, $9.03 \mathrm{ng} / \mathrm{dL}$ increase in resistin level was observed.

And in SGA-term group:

1. Resistin level had a positive correlation with gestational age $(\mathrm{P}=0.041)$.

2. For every one unit (one week) increase in gestational age, $3.89 \mathrm{ng} / \mathrm{dL}$ increase in resistin level was observed.

\section{Discussion}

The present study was done to find an answer to the conflicting results of previous studies regarding the association of cord blood resistin, neonatal birth weight, and gestational age. We have revealed that cord blood resistin has a reverse correlation with birth weight in SGA-preterm neonates. For every one unit ( $1 \mathrm{~g}$ ) increase in birth weight, $0.045 \mathrm{ng} / \mathrm{dL}$ decrease in resistin level was observed. In addition, in these neonates, resistin had a positive correlation with gestational age. For every one unit (one week) increase in gestational age, $9.03 \mathrm{ng} / \mathrm{dL}$ increase in resistin level was observed. Furthermore, in SGA-term neonates, cord blood resistin level had a positive correlation with gestational age. On the other hand, for every one unit (one week) increase in gestational age, $3.89 \mathrm{ng} / \mathrm{dL}$ increase in resistin level was observed. We suggest that the conflicting results in previous reports might be due to the fact that resistin could have two separate mechanisms on gestational age and birth weight, the first one is positive and the second is a reverse association. Furthermore, the association with gestational age might be greater than that of birth weight. Future studies are needed to prove this hypothesis.

Some previous reports showed that resistin in term infants was higher than preterm ones and it was related to the gestational age $(7,9)$. Martos-Moreno et al. revealed that gestational age was a strong predictor of higher cord blood resistin in preterm Spanish neonates (15). In addition, a large sample size study in the USA found an important assertion between serum adipokines including resistin and preterm birth (11). However, some studies showed that the umbilical cord blood resistin was not different in term and preterm neonates $(8,10,16,17)$. 
We showed that in SGA-preterm and SGA-term neonates, neonates resistin had positive correlation with gestational age.

On the other hand, association of resistin and birth weight was proposed by some researches (11, 18-20). Resistin opposes the action of insulin and affects insulin sensitivity (21). In addition, adiponectins and resistin have an important role in controlling body weight and are related to the occurrence of fetal macrosomia (14). Similar to our results, some other studies have found a reverse correlation between resistin level and birth weight $(8,14)$. Yeung et al. demonstrates the association between preterm delivery and SGA with adipokines (11). However, a recent study did not find any association between birth weight and serum adipokines and suggested that it may due to gestational age having a greater effect on adiponectins at birth (22). Furthermore, another research showed that in GDM complicated pregnancies, serum resistin was not different in SGA and LGA infants (19). In Chinese newborns, resistin was not associated with either birth weight or other neonatal anthropometric measures (17). We showed that just in SGA-preterm newborns, resistin level had a reverse correlation with birth weight.

The strength of this study was the large sample size with systematized categories and being able to attain an important and interesting suggestion for the cause of conflicts mentioned in previous reports about the association of resistin and neonatal gestational age and birth weight. In spite of these, there were some limitations. To have a better report, the maternal blood resistin should be assessed, which was not considered in this study. In addition, other adipokines should be checked to find the confounding effects.

\subsection{Conclusion}

Cord blood resistin has a positive correlation with gestational age and a reverse association with neonatal birth weight. We suggest that these two different associations might be the cause of conflicting results in previous reports.

\section{Footnotes}

Authors' Contribution: Formulating the research questions and designing the study: Shahnaz Pourarian, Forough Saki, and Saeed Fotouhikia; analysing the data and writing the article: Forough Saki.

Conflict of Interests: The authors declare no conflict of interest.

\section{References}

1. Steppan CM, Bailey ST, Bhat S, Brown EJ, Banerjee RR, Wright $\mathrm{CM}$, et al. The hormone resistin links obesity to diabetes. Nature. 2001;409(6818):307-12. doi: 10.1038/35053000. [PubMed: 11201732].

2. Kim KH, Lee K, Moon YS, Sul HS. A cysteine-rich adipose tissuespecific secretory factor inhibits adipocyte differentiation. J Biol Chem. 2001;276(14):11252-6. doi: 10.1074/jbc.C100028200. [PubMed: 11278254].

3. Reilly MP, Lehrke M, Wolfe ML, Rohatgi A, Lazar MA, Rader DJ. Resistin is an inflammatory marker of atherosclerosis in humans. Circulation. 2005;111(7):932-9. doi: 10.1161/01.CIR.0000155620.10387.43. [PubMed: 15710760].

4. Shetty GK, Economides PA, Horton ES, Mantzoros CS, Veves A. Circulating adiponectin and resistin levels in relation to metabolic factors, inflammatory markers, and vascular reactivity in diabetic patients and subjects at risk for diabetes. Diabetes Care. 2004;27(10):2450-7. [PubMed: 15451915].

5. Rajala MW, Qi Y, Patel HR, Takahashi N, Banerjee R, Pajvani UB, et al Regulation of resistin expression and circulating levels in obesity, diabetes, and fasting. Diabetes. 2004;53(7):1671-9. [PubMed: 15220189].

6. Le Lay S, Boucher J, Rey A, Castan-Laurell I, Krief S, Ferre P, et al. Decreased resistin expression in mice with different sensitivities to a high-fat diet. Biochem Biophys Res Commun. 2001;289(2):564-7. doi: 10.1006/bbrc.2001.6015. [PubMed: 11716511].

7. $\mathrm{Ng} \mathrm{PC}$, Lee $\mathrm{CH}$, Lam $\mathrm{CW}$, Chan IH, Wong E, Fok TF. Resistin in preterm and term newborns: Relation to anthropometry, leptin, and insulin. Pediatr Res. 2005;58(4):725-30. doi: 10.1203/01.PDR.0000180556.76864.9A. [PubMed: 16189200].

8. Farid SD, Najati N, Gharebaghi MM, Haghjo AG, Ghojazadeh M. Resistin in cord blood of small for gestation age and appropriate for gestation age term neonates. Iran J Pediatr. 2013;23(6):659-63. [PubMed: 24910744]. [PubMed Central: PMC4025123].

9. Cortelazzi D, Corbetta S, Ronzoni S, Pelle F, Marconi A, Cozzi V, et al. Maternal and foetal resistin and adiponectin concentrations in normal and complicated pregnancies. Clin Endocrinol (Oxf). 2007;66(3):447-53. doi: 10.1111/j.1365-2265.2007.02761.x. [PubMed $17302882]$.

10. Fotouhikia S, Pourarian S, Setoodehnia Z, Javanmardi H, Saki F. Investigating the association of cord blood resistin and birth weight in term and preterm neonates. Int J Pediatr. 2016;4(11):3769-75. doi: 10.22038/ijp.2016.7479.

11. Yeung EH, McLain AC, Anderson N, Lawrence D, Boghossian NS, Druschel C, et al. Newborn adipokines and birth outcomes. Paediatr Perinat Epidemiol. 2015;29(4):317-25. doi: 10.1111/ppe.12203. [PubMed: 26111443]. [PubMed Central: PMC4484786].

12. Battaglia FC, Lubchenco LO. A practical classification of newborn infants by weight and gestational age. J Pediatr. 1967;71(2):159-63. [PubMed: 6029463].

13. Ballard JL, Khoury JC, Wedig K, Wang L, Eilers-Walsman BL, Lipp R. New Ballard Score, expanded to include extremely premature infants. JPediatr.1991;119(3):417-23. doi:10.1016/s0022-3476(05)82056-6.

14. Wang J, Shang LX, Dong X, Wang X, Wu N, Wang SH, et al. Relationship of adiponectin and resistin levels in umbilical serum, maternal serum and placenta with neonatal birth weight. Aust $N$ Z J Obstet Gynaecol. 2010;50(5):432-8. doi: 10.1111/j.1479-828X.2010.01184.X. [PubMed: 21039376].

15. Martos-Moreno GA, Barrios V, Saenz de Pipaon M, Pozo J, Dorronsoro I, Martinez-Biarge $\mathrm{M}$, et al. Influence of prematurity and growth restriction on the adipokine profile, IGF1, and ghrelin levels in cord blood: Relationship with glucose metabolism. Eur J Endocrinol. 2009;161(3):381-9. doi: 10.1530/EJE-09-0193. [PubMed: 19561044].

16. Kominiarek MA, Gambala CT, Sutherland M, Varady K. Adipokinins in pregnancies at risk of preterm delivery. Gynecol Endocrinol. 2016;32(1):78-81. doi: 10.3109/09513590.2015.1092133. [PubMed: 26426452]. [PubMed Central: PMC4868387]. 
17. Ng PC, Lee $\mathrm{CH}$, Lam CW, Wong E, Chan IH, Fok TF. Plasma ghrelin and resistin concentrations are suppressed in infants of insulin-dependent diabetic mothers. J Clin Endocrinol Metab. 2004;89(11):5563-8. doi: 10.1210/jc.2004-0736. [PubMed: 15531512].

18. Solis-Paredes M, Espino YSS, Estrada-Gutierrez G, Nava-Salazar S Ortega-Castillo V, Rodriguez-Bosch M, et al. Maternal and fetal lipid and adipokine profiles and their association with obesity. Int Endocrinol. 2016;2016:7015626. doi: 10.1155/2016/7015626. [PubMed: 27190514]. [PubMed Central: PMC4844894].

19. Nanda S, Nikoletakis G, Markova D, Poon LC, Nicolaides KH. Maternal serum retinol-binding protein-4 at 11-13 weeks' gestation in normal and pathological pregnancies. Metabolism. 2013;62(6):814-9. doi: 10.1016/j.metabol.2012.12.011. [PubMed: 23410747].

20. Kotani Y, Yokota I, Kitamura S, Matsuda J, Naito E, Kuroda Y. Plasma adiponectin levels in newborns are higher than those in adults and positively correlated with birth weight. Clin Endocrinol (Oxf). 2004;61(4):418-23. doi: 10.1111/j.1365-2265.2004.02041.x. [PubMed: 15473872].

21. Park HK, Ahima RS. Resistin in rodents and humans. Diabetes Metab J. 2013;37(6):404-14. doi: 10.4093/dmj.2013.37.6.404. [PubMed: 24404511]. [PubMed Central: PMC3881324].

22. Fonseca MJ, Santos AC. Umbilical cord blood adipokines and newborn weight change. Arch Gynecol Obstet. 2015;291(5):1037-40. doi: 10.1007/s00404-014-3534-8. [PubMed: 25384519]. 